\title{
CONSIDERAÇÕES SOBRE OS INSTRUMENTOS PROCESSUAIS HOJE DISPONÍVEIS NA DEFESA DOS DIREITOS TRANSINDIVIDUAIS
}

\section{Jordete se Oliveira Franco Gomes}

Especialista em Direito Processual pela FA7. Advogada e engenheira-civil. jordetefg@gmail.com

Sumário: Introdução. 1) A evolução da estrutura processual brasileira. 2) AAção Civil Pública. 3) O Código de Defesa do Consumidor e a Lei da Ação Civil Pública, conjuntamente aplicados na tutela dos direitos transindividuais 4) Crítica ao sistema adotado. Considerações finais.

\begin{abstract}
Resumo: O presente trabalho objetiva discorrer sobre os instrumentos processuais disponíveis visando à solução dos conflitos transindividuais, sua aplicabilidade e principais dificuldades processuais inerentes à própria complexidade do bem tutelado, onde se insere o enfrentamento da questão ambiental. A lei, para atender, deve ser apreendida e aplicada como uma proposição cujo sentido se modifica à medida em que também as demandas, as contingências históricas, sociais e ideológicas são modificadas. Este trabalho procura demonstrar que a constante formulação de novas atitudes e práticas são o caminho para aproximar a sociedade da justiça.
\end{abstract}

Palavras-chave: Direitos coletivos. Direitos transindividuais. Meio ambiente. Estatuto da Cidade. Agenda 21.

\section{INTRODUÇÃo}

A cada dia é mais atuante a defesa dos interesses/direitos transindividuais no Brasil, entendidos, para o desenvolvimento deste trabalho, como os interesses fora dos individualmente considerados, quais sejam os interesses difusos e coletivos, em razão de sua indivisibilidade. Embora não haja ainda um regramento processual específico e adequado sobre execuções coletivas, o que se justifica em face do recente o movimento de coletivização do direito processual, já se pode contar com uma boa produção doutrinária, jurisprudencial e, o mais importante, um projeto 
de lei hoje em trâmite no Congresso Nacional a estabelecer o Código Brasileiro de Processos Coletivos.

Essas novas demandas, não necessariamente relacionadas ao número de sujeitos lesados e sim à gravidade que representam para o tecido social, são resultantes dos conflitos nascidos a partir de concentrações urbanas sem controle, da incontinência da produção e do consumo, das mudanças climáticas e suas conseqüências imprevisíveis, apenas para citar as mais recorrentes (ROCHA, 2001, p. 5). Os crescentes riscos para a biodiversidade representam problemas de grande monta que ameaçam não somente o homem, mas todo o ecossistema do planeta. Proteger o meio ambiente é uma prioridade a lançar desafios às instituições jurídicas clássicas, sobretudo perante o processo civil. A Constituição define o meio ambiente ecologicamente equilibrado como direito de todos e lhe dá natureza de bem de uso comum do povo e essencial à sadia qualidade de vida. Também impõe a co-responsabilidade do cidadão e do Poder Público pela sua defesa e preservação (art. 225, caput) É um direito que não pertence nem ao Estado, nem ao indivíduo isoladamente considerado, por isso, depende tanto da existência de mecanismos processuais adequados aos conflitos, quanto da atuação dos seus aplicadores ao interpretar e adaptar esses novos instrumentos às demandas. Segundo Gómez (2001, p. 3), essas normas jurídicas, compostas em legislação especial, representam verdadeiros instrumentos de engenharia social que o Estado utiliza para fazer valer concretamente a justiça e proteger determinados interesses sociais.

A título de exemplo, o Estatuto da Cidade, Lei 10.257 de 10 de julho de 2001, veio regulamentar os artigos 182 e 183 da Constituição Federal. Traça as diretrizes gerais para o ordenamento urbano com grande ênfase ao planejamento municipal, ao equilíbrio ambiental, numa preocupação constante com a necessidade de preservar a natureza, corrigir os erros e inconseqüências com a maior brevidade, enfrentando novas realidades e novos problemas jurídicos. Seu art. 41 obriga municípios com mais de vintém mil habitantes, cidades integrantes de regiões metropolitanas e aglomerações urbanas, as integrantes de áreas de especial interesse turístico e as inseridas na área de influência de empreendimentos e atividades com significativo impacto ambiental de caráter regional ou nacional a terem seus Planos Diretores participativos.

Os instrumentos da política urbana contidos nesse estatuto, segundo Silva (2006, p. 69), lhe dão características de uma Lei Geral de Direito Urbanístico quando disponibilizam ao poder municipal, através de seus Planos Diretores Participativos, condições de, poder público e sociedade atuando juntos, proporem à cidade melhores formas de desenvolvimento e expansão urbana ordenada, melhor administração das reservas fundiárias do município e dos terrenos desapropriados. Tais mecanismos são importantes para regular o mercado imobiliário, facilitar o desenho e execução do planejamento urbano, além da utilização adequada do solo urbano. 
No mesmo caminho está a Agenda 21, um dos documentos mais importantes produzidos na Conferência das Nações Unidas sobre o Meio Ambiente e Desenvolvimento-ECO-92, a propor transformações significativas nos valores e na cultura que fundamentam a vida na sociedade capitalista, estimulando mudanças em seus modos de produção e consumo, estes reconhecidamente insustentáveis. Tem como fundamento uma série de reflexões e propostas que tratam de temas nas áreas ambiental, social, econômica e política, constituindose, desta forma, em um importante instrumento para a implementação de um novo modelo de desenvolvimento econômico e social, que seja verdadeiramente sustentável e garanta, não somente a qualidade do meio ambiente, mas também a qualidade de vida dos que nele habitam. Nesse sentido, a Agenda 21, mais que um simples documento, é o resultado de um compromisso, um programa de ação contínua de todas as nações e povos, em prol de um desenvolvimento que tenha como objetivo a promoção do bem comum, o respeito e a responsabilidade social com o presente e o futuro.

Esses dois dispositivos, o Plano Diretor e a Agenda 21, têm em comum a participação popular como elemento indispensável para suas formações. Precisam também de ações descentralizadas, inserções de suas pautas nos programas de governo em todos os níveis e responsabilidades para que, a longo prazo, as abordagens e propostas sejam internalizadas por todos os setores da sociedade e promovam transformações sociais eficazes. Já não se admite mais, em uma administração municipal, atos que sejam contrários aos interesses da sociedade organizada.

Em resposta à evolução do papel assumido pela sociedade, o Judiciário percebeu a necessidade de garantir respostas adequadas às crescentes demandas coletivas, em relação à satisfação de uma pretensão comum e fez surgir instrumentos jurídicos para tutelar direitos difusos e coletivos, dentre eles, a ação popular e o mandado de segurança coletivo (MENDES, 2008, p. 1).

Negreiros (2007, p. 187), que toma como referência J. M. Othon Sidou, discorre que, historicamente, a construção jurídica latina, apesar de deu peculiar individualismo, sempre concedeu espaço a causas pro populo, em nome alheio, pela liberdade.

No caminho desses interesses difusos, houve dois momentos definitivos. Primeiro, a edição da Lei 7.347 de 24 de julho de 1985 - Lei da Ação Civil Pública - LACP e do Código de Defesa do Consumidor-CDC, Lei 8.078 de 11 de setembro de 1990, ambas responsáveis pelo maior desenvolvimento e suporte à defesa dos interesses coletivos.

Sabe-se do longo trabalho a ser realizado na superação das divergências naturais, diante de conceitos tão diferentes das relações intersubjetivas, que balizam o ordenamento processual civil tradicional, mas é assim que o Direito se faz vivo. 


\section{A EVOLUÇÃo DA ESTRUTURA PROCESSUAL BRASILEIRA}

O homem é a meta para onde se conduzem todos os ramos da ciência jurídica e à medida que ele se insere no meio social, fica evidente a fragilidade da regra do limite subjetivo dos efeitos da sentença, herança do direito romano. Os atos jurídicos podem, sim, ultrapassar os limites entre as partes envolvidas na questão judicial e atingir, ainda que de forma menos direta, terceiros alheios ao processo, porém ligados ao objeto material da disputa judicial. Esse reconhecimento tem exigido do Direito a rápida evolução nesse caminho para dar respostas a essas demandas (REGO, 2006, p. 2).

A evolução da estrutura processual que trata de direitos coletivos no Brasil pode ser dividida em duas fases. A primeira trouxe:

- a introdução de novos mecanismos com a finalidade de dar curso às demandas coletivas via ação civil pública, ação popular e ações de improbidade;

- a tutela de direitos e interesses transindividuais com a definição legal desses direitos e interesses e

- a tutela de forma abstrata à ordem jurídica pela ampliação do controle abstrato de constitucionalidade.

A segunda fase veio aperfeiçoar e ampliar os mecanismos já existentes pela reformulação de todo o processo civil visando à obtenção de maior efetividade na prestação jurisdicional por intermédio dos seguintes dispositivos:

- alterações na estrutura dos recursos;

- nova sistemática na execução e

- unificação das tutelas de urgência por antecipação.

O novo e atual sistema processual tem hoje três caminhos:

- tutela de direitos individuais por meio de tutela individual ou coletiva, com substituição processual;

- tutela de direitos transindividuais por meio de ação popular, ação civil pública e ação de improbidade administrativa;

- tutela de ordem jurídica pelos mecanismos de controle de constitucionalidade.

Essa evolução se encontra materializada numa sequência de leis, consideradas a partir da Lei 7.347/1985 que incorporou a ação civil pública ao vocabulário jurídico, a saber:

Lei 7.853 de 24 de outubro de 1989 - dispõe sobre a ação civil pública em apoio às pessoas portadoras de deficiência (arts. $3^{\circ} \mathrm{a} 7^{\circ}$ ).

Lei 8.069 de 13 de julho de 1990 - dispõe sobre o Estatuto da Criança e do Adolescente (arts. 209 a 224). 
Lei 8.078 de 11 de setembro de 1990 - Código de Defesa do Consumidor (arts. 91 a 100).

Lei 10.741 de 01 de outubro de 2003 - Estatuto do Idoso (art. 74).

Lei 10.257/2001 - Estatuto da Cidade (art. 52).

Tais mudanças têm promovido um movimento de renovação do processo civil no sentido de buscar maior efetividade às demandas nascidas no seio da dinâmica social.

\section{A Ação Civil Pública}

Antes da lei 7.347/1985, o ordenamento jurídico já dispunha de um mecanismo processual de defesa de interesses coletivos: a ação popular. Existe, no ordenamento jurídico brasileiro, a Lei 4.717 de 29 de junho de 1965, onde seu artigo $1^{\circ}$ já considerava os direitos difusos e previa a condição de um único cidadão poder ingressar em juízo para solicitar a intervenção da justiça.

Posteriormente, com a Lei 6.938 de 31 de agosto de 1981, sobre a Política Nacional do Meio Ambiente, a responsabilidade civil para a reparação do dano ambiental passou a ser objetiva, dispensando a comprovação de culpa do poluidor do meio ambiente.

A Constituição de 1988 contempla, em seu art. $5^{\circ}$, LXXIII a defesa do patrimônio público, moralidade administrativa, meio ambiente e o patrimônio histórico e cultural. Há também no mesmo diploma, art. $5^{\circ}$, LXX, o mandado de segurança coletivo, que pode ser impetrado por partido político com representação no Congresso Nacional, organização sindical, entidade de classe ou associação legalmente constituída e em funcionamento há, pelo menos, um ano, em defesa dos interesses de seus membros ou associados. Excepcionalmente, pode uma associação com menos de um ano de constituição impetrar ação, desde que se trate de matéria relevante. O que não se permite é a criação de entidade com o fim exclusivo de impetrar uma ação. É peculiar, por ser um direito atribuído a entes públicos e privados para a tutela de interesses não-individuais.

$\mathrm{O}$ final do século XX trouxe um novo modelo econômico-social marcado pela crescente urbanização, concentração de capital e pela forma imprevisível, imensurável e indeterminada dos danos causados, em especial, ao meio ambiente. O dano ambiental, sabe-se, é de difícil reparação e ainda mais difícil sua valoração. Por isso, o meio ambiente é reconhecido como bem jurídico e sua degradação entendida como elemento de interferência direta na dinâmica social, econômica e política, capaz de atingir todos os seres vivos indistintamente. Temas como a proteção do meio ambiente, os contratos de massa e as relações sociais passaram a exigir do direito a criação de instrumentos mais eficientes e capazes de garantir uma tutela jurisdicional efetiva. 
Assim, a Lei 7.347/1985 apresenta-se como um instrumento mais aperfeiçoado e adequado à proteção dos direitos difusos ao contemplar em seu bojo a legitimação para a defesa em juízo dos direitos coletivos, a ampliação dos efeitos subjetivos da coisa julgada e a previsão e regulamentação de meios de tutela preventiva dos direitos coletivos. Estes mecanismos encontram adequação quando utilizados na defesa contra condutas causadoras de danos ao meio ambiente, ao consumidor, a bens e direitos de valor artístico, estético, histórico, turístico e paisagístico (MENDES, 2008, p. 02). No entanto, tal instituto deve ser usado com cautela para não se tornar um instrumento de vingança, em razão da inversão da polaridade ativa e passiva.

A Constituição Federal, posteriormente, reconheceu expressamente a existência de interesses difusos e garantiu, no art. 129, III, a inclusão da ação civil pública às funções institucionais do Ministério Público que teve seu campo de atuação ampliado não só para a proteção do patrimônio público, social e do meio ambiente, mas também para a guarda de outros interesses difusos e coletivos. Assim, de acordo com o art. $5^{\circ}$ da Lei 7.347/1985, são legitimados para propor a ação principal e a ação cautelar o Ministério Público, a Defensoria Pública, as pessoas jurídicas da Administração Indireta (União, Estados, Distrito Federal e Municípios), as pessoas jurídicas da Administração Pública e as associações que estejam constituídas há pelo menos um ano e que tenham em seus fins institucionais a previsão do objeto a ser tutelado em juízo (FREITAS FILHO, 2007, p. 3).

A titularidade do Ministério Público atualmente é bastante ampla e, com a criação da Advocacia Geral da União (AGU), passou a ter plena independência para demandar instrumentos de tutela coletiva. Ao cidadão cabe uma titularidade restrita, considerando que a ação popular somente pode ter por objeto a anulação de ato lesivo ao patrimônio público ou à entidade de que o Estado participe, à moralidade administrativa, ao meio ambiente e ao patrimônio histórico e cultural.

\subsection{TUTELA INIBITÓRIA E TUTELA REPARATÓRIA da AÇão Civil Pública}

A ação civil pública pode atuar preventivamente ao dano como se vê nos artigos da Lei 7.347/1985, conforme Pilati (2008, p. 3-5):

a) Art. $3^{\circ}$ - possibilidade de condenação em dinheiro ou cumprimento de obrigação de fazer ou não fazer.

b) Art. 11 - possibilidade de o juiz determinar o cumprimento de obrigação de fazer ou não fazer através de prestação ou cessação de atividade, sob pena de execução específica ou cominação de multa, independente de requerimento do autor

c) Art. 12 - possibilidade de o juiz conceder mandado liminar, com ou sem justificação prévia, em decisão sujeita a agravo. 
Também no Código de Processo Civil-CPC, através dos artigos:

a) Art. 287 - no pedido, o autor poderá requerer a cominação de pena pecuniária para o caso de descumprimento da sentença ou da decisão antecipatória de tutela.

b) Art. $461, \S 4^{\circ}$ - pode o juiz impor multa diária ao réu, independente do pedido do autor, se for compatível com a obrigação, fixando-lhe prazo

Ainda no artigo 84 do CDC, em ações que tenham por objeto o cumprimento de obrigação de fazer ou não fazer, o juiz pode conceder a tutela específica da obrigação ou determinará providências que assegurem o resultado prático equivalente ao adimplemento.

Todos eles assinalam para a obrigação de fazer ou não fazer, com mandado liminar, prevenindo a ocorrência do dano ou ainda para a ação repressiva, após o evento danoso, com o intuito de ressarci-lo.

A tutela inibitória lato sensu é aplicável a situações em que se verifica o ilícito, sem ocorrência de dano. Tem como fundamento os princípios da prevenção e da precaução. Para o princípio da preocupação há de se estabelecer a prioridade que deve ser dada a medidas que evitem o nascimento de riscos ou impactos ao ambiente para reduzir ou eliminar as causas de ações suscetíveis de alterar sua qualidade. Também inibitória, a precaução é um estágio além da prevenção e se destina a gerir riscos ou impactos ainda desconhecidos e/ou incertos, abstratos. Este princípio tem outra relevante conseqüência, qual seja a de impor ao degradador o ônus de provar que a atividade questionada não é efetiva ou potencialmente degradadora, invertendo o ônus da prova. Assim, a precaução tende a não se realizar e, havendo risco de dano irreversível, a prevenção busca, ao menos em um primeiro momento, a compatibilização entre a atividade e a proteção ambiental. A sua efetivação pode se dar através da tutela inibitória ou tutela de remoção do ilícito (MILARÉ, 2007, p. 765-769). É inibitória quando objetiva impedir a prática ou continuação do ilícito. Neste caso, sem que haja configuração de dano, impõe-se ao agente medida coercitiva de fazer ou não fazer pela aplicação de multa. Essa multa deve ser aferida na sua realidade, variando entre o mínimo vital e o confisco. A realização da tutela inibitória encontra grandes dificuldades na sua produção de provas, pois de que forma é possível provar, de forma idônea e capaz, um temor diante da possibilidade concreta de ocorrência do ilícito, e ainda comprovar sua contrariedade à lei? Por conta disso, se aceita a verossimilhança.

A tutela de remoção de ilícito atua num segundo estágio, entre a ocorrência do ilícito (arts. 186 usque 188 Código Civil-CC) e a constatação do dano, determinando-se o cumprimento da obrigação por terceiro e à expensa do causador do ilícito.

A tutela reparatória destina-se à reparação do dano já ocorrido. Quando produzido o dano e configurado o prejuízo é preciso buscar meios de ressarcimento e reparação dos danos causados individual e coletivamente. O causador da 
poluição, por exemplo, arca com os custos necessários à diminuição, eliminação ou neutralização do dano causado, pois, aquele que lucra deve responder pelo risco ou pela desvantagem dela resultante. A responsabilidade civil, em acepção ampla, prevista no art. 927 do CC, determina que "aquele que, por ato ilícito causar dano a outrem, fica obrigado a repará-lo". A responsabilidade civil prevê a obrigação de reparar danos causados por ações ou omissões dolosas ou culposas.

Há ainda a possibilidade de se buscar uma saída negociada para a reparação dos danos a interesses difusos e coletivos pela aplicação do "compromisso de ajustamento de conduta", conforme art. $5^{\circ}, \S 6^{\circ}$ (dispositivo semelhante há também no art. 211 da lei $n^{\circ}$ 8.069/90 - Estatuto da Criança e do Adolescente-ECA).

$\mathrm{O}$ referido instrumento possibilita à parte, a quem se imputa a ofensa dos interesses coletivos, que harmonize o seu comportamento às exigências da lei. Esses acordos visam, sobretudo, não ao interesse de "vencer" a causa e sim a obter, de modo menos oneroso e menos impactante, a melhor tutela para o conflito, entendendo que é "melhor um mau acordo que uma boa demanda" (MILARÉ, 2007, p. 976-986). Embora o compromisso reclame sempre a reparação integral do dano, há também previsão de multas pecuniárias para o caso de não cumprimento e os recursos são destinados a fundos que têm como objetivo a reparação dos danos ocasionados. Têm força de título executivo extrajudicial.

\section{Código de Defesa do Consumidor e a Lei da Ação Civil PÚblica, CONJUNTAMENTE APLiCAdos Na TUTEla DOS DIREITOS TRANSINDIVIDUAIS}

A Constituição Federal contém três artigos que tratam da proteção ao consumidor dentro da relação de consumo como direito fundamental e como princípio da ordem econômica (SMANIO, 2004, p. 4). São eles os artigos:

a) art. $5^{\circ}, \mathrm{XXXII}$ - a defesa do consumidor.

b) art. $150, \S 5^{\circ}$ - esclarecimentos aos consumidores acerca dos impostos que incidam sobre mercadorias e serviços.

c) art. 170, V-assegurar à ordem econômica o princípio da defesa do consumidor.

São regras de caráter obrigatório e inderrogáveis pelo interessado. Além de sua importância por si, teve ainda o condão de preencher algumas lacunas da LACP e formado junto com ela uma jurisdição civil coletiva com técnicas processuais diferentes para atender às tutelas de direitos transindividuais. Sua finalidade, expressa no art. $1^{\circ}$, IV, da LACP é dar flexibilidade ao texto legal, prevendo as rápidas mutações de modo a permitir sua adaptação às novas situações concretas ainda não imaginadas pelo legislador, mas que se encaixem nos parâmetros 
da coletividade, que são os fundamentos da ação civil pública. Esses dois diplomas foram visceralmente integrados pelo art. 21 da LACP, com redação dada pelo art. 117 do CDC, o que tornou a Ação Civil Pública um instrumento eficaz na defesa dos interesses difusos, coletivos ou individuais homogêneos (ALMEIDA, 2004. p. 02).

Na verdade, o CDC não regula todo o processo coletivo, seu objetivo maior é outro, mas, em seu texto os conceitos uniformizados e capazes de integrar ao regime jurídico-processual esses novos direitos (MENDES, 2008, p.03).

Outra importante contribuição do CDC foi ter apresentado a conceituação de interesses difusos (art. 81, I), coletivos, assim entendidos os transindividuais (art. 81, II) e os individuais homogêneos (art. 81, III). O vocábulo difuso, segundo o dicionário Aurélio da Língua Portuguesa, significa disseminado, divulgado, prolixo, redundante. No plano do Direito, como conceituado no CDC, a expressão difuso, no sentido de direito ou interesse, significa espécie de direito de dimensão coletiva pertencente a uma comunidade de pessoas indeterminadas e indetermináveis, mas que é de um e de todos ao mesmo tempo. É caracterizado pela pulverização de vítimas, mesmo que certos aspectos de sua danosidade possam atingir, de forma individual, certos sujeitos. Afinal, a quem pertence a titularidade do ar que respiramos? É óbvio, pertence a cada um e a todos ao mesmo tempo, daí a circunstância fática, absoluta, da sua indivisibilidade (ROCHA, 20019, p.09-14).

Nos direitos ou interesses difusos não existe prévia relação jurídica, pois as pessoas estão ligadas por meras circunstâncias fáticas, ao passo que, nos coletivos, em sentido estrito, torna-se importante a existência de uma prévia relação jurídica entre os membros da categoria, classe ou grupo de pessoas ou entre essas pessoas e a parte contrária. Portanto, é considerado direito difuso o direito de respirar ar puro, de não ser alvo de publicidade enganosa e abusiva, o direito da comunidade sobre a integralidade do patrimônio cultural, moral, ecológico, o direito a ter os serviços essenciais com solução de continuidade, e tantos outros.

Observa-se o art. $5^{\circ}, \S 2^{\circ}$ da CRFB:

Os direitos e garantias expressos nesta Constituição não excluem outros decorrentes do regime democrático e dos princípios por ela adotados, ou dos tratados internacionais em que a República Federativa do Brasil seja parte.

O dispositivo acima deixa claro que a relação dos direitos difusos apresentados expressamente na Constituição é meramente exemplificativa. Podem ser extraídos outros direitos difusos do seu próprio espírito e de outras normas jurídicas compatíveis com o Estado Democrático de Direito e em vigência no Brasil. Adequa-se aqui o princípio da não-taxatividade do direito coletivo.

A partir desses conceitos legais é possível haver um acoplamento entre a estrutura processual tradicional e esse novo atuar dirigido aos interesses transindividuais, muito embora seja desejável a construção de uma estrutura própria. 
Ressalte-se que o Título III do CDC não é o único local em que se pode buscar fundamento para as tutelas coletivas. Outras regras processuais se encontram no mesmo diploma, tais como:

a) Art. $5^{\circ}, \mathrm{I}$ - assistência jurídica integral e gratuita ao consumidor carente;

b) Art. $6^{\circ}$, VI e VIII - prevenção e tratamento diferenciado possibilitando a inversão do ônus da prova, este disposto no art. 333 do Código de Processo Civil-CPC, que se dá por convencimento do juiz;

c) Art. $43, \S 4^{\circ}$ - acesso a informações (habeas data);

d) Art. 117 - aplicação das normas processuais do Título III à tutela de outros interesses difusos, coletivos e individuais homogêneos;

e) Arts.109 usque 117 - ampliação do âmbito de atuação da Lei 7347/1985 com incidência das regras do CDC.

De fato, o CDC e a LACP são diplomas irmãos que promoveram um movimento de renovação do processo civil, ao tratar de interesses não mais considerados individualmente, mas em sua acepção coletiva e difusa. Todos os dispositivos que garantem direitos processuais no CDC também estão incluídos na ação civil pública, pois o espírito da norma é fazer a com que as inovações processuais trazidas pelo CDC também alcancem a LACP (PILATI, 2008, p. 6).

\section{Crítica ho SiSTema adotado}

O sistema brasileiro, no contexto da tutela jurisdicional dos direitos coletivos, é considerado um dos mais avançados do mundo. Consagra amplamente os valores da tutela jurídica material coletiva, quando os insere no bojo dos direitos fundamentais (Título II, Capítulo I, art. $5^{\circ}$, da CRFB de 1988), garantindo o acesso amplo e irrestrito à justiça ( art. $\left.5^{\circ}, \mathrm{XXXV}\right)$, o mandado de segurança coletivo (art. $5^{\circ}$, LXX), o mandado de injunção (art. $\left.5^{\circ}, \mathrm{LXXI}\right)$, a proposição da ação popular (art. $5^{\circ}$, LXXIII), a ponto de tornar-se imprescindível também a concepção de um direito processual coletivo.

Contrariamente à legitimação adotada nas ações civis públicas consagradas na regra 23 da Federal Rules of Civil Procedure norte-americana. Não há na LACP a figura do ideological plaintiff (autor ideológico), muito embora possamos têla presente na Lei 4.717 de 29 de junho de 1965, que regula a ação popular, ao legitimar qualquer cidadão a pleitear anulação ou declaração de nulidade de atos lesivos ao patrimônio público. $\mathrm{O}$ argumento utilizado por alguns defensores baseiase no risco da utilização da ação popular como instrumento político de pressão, sobretudo no que diz respeito a questões que tratem de moralidade administrativa. $\mathrm{Na}$ verdade, se cabe ação popular, independentemente de somente um cidadão impetrá-la, há interesse público na defesa da moralidade administrativa. Daí a 
irrenunciabilidade da ação popular, prevista no art. $9^{\circ}$ da Lei 4717/1965, que dispõe a interveniência do Ministério Público em caso de desistência por parte do autor da ação. Esta vinculação jurídica mitiga a intenção de pressões contrárias exercidas pelo réu com o objetivo de desestimular ou oferecer vantagens pessoais em troca da desistência da ação. Portanto, não se trata de argumento capaz de justificar tal limitação (AGUILAR, 2000, p. 5).

Sabe-se que nenhum regramento nasce completo. É sua aplicação, com erros e acertos, que o tornará efetivamente um instrumento em favor do direito.

\section{CONSIDERAÇÕes FINAIS}

O objeto formal do direito processual coletivo é composto pelo conjunto de princípios, garantias e regras processuais que disciplinam o exercício da ação coletiva, da jurisdição coletiva, do processo coletivo, da defesa no processo coletivo e da coisa julgada coletiva. Além das disposições constitucionais consagradoras de princípios, garantias e regras processuais próprias, o objeto formal do direito processual coletivo ainda se compõe das seguintes leis:

a) Código de Defesa do Consumidor — Lei 8.078/90 - Título III, art. 90;

b) Lei da Ação Civil Pública - 7.347/85, art. 21;

c) Lei $9.868 / 90$ - processo e julgamento de ADIN e ADC pelo STF;

d) Lei 9.882/90 - processo e julgamento de ADPF.

O CPC integra o objeto formal do direito processual coletivo, mas de forma subsidiária, limitada e também provisória. Ainda que a Constituição Federal garanta o acesso para apreciação de violações a interesses transindividuais, espera-se que, num tempo breve, se concretize um sistema mais completo, capaz de romper de vez com todas as amarras individualistas do CPC. Esse é um dos grandes desafios do movimento pela codificação do direito processual coletivo brasileiro, na busca de tornar mais uniforme e mais visível o objeto formal do direito processual coletivo, o que só será adequado quando respeitadas as diretrizes constitucionais consagradoras do direito processual coletivo como novo ramo do direito processual brasileiro.

Espera-se que essa proposta de codificação, com técnicas legislativas atualizadas, consiga expressar a complexidade social, econômica e política da vida contemporânea e traduzir as mudanças e transformações dos valores e princípios que caracterizam a atual organização social. 


\section{REFERÊNCIAS}

Agenda 21. Disponível em: http://www.ecolnews.com.br/agenda21/index.htm. Acesso em: 07 set. 2009.

AGUILAR, Rafael Pinheiro. Por uma legitimação individual nas ações coletivas. Jus Navigandi, Teresina, ano 5, n.48, dez. 2000. Disponível em: http:// jus2.uol.com.br/doutrina/texto.asp?id=349. Acesso em: 26 out. 2008.

ALMEIDA, Renato Franco de; GAMA, Paulo Calmon Nogueira da. A competência nas ações coletivas do CDC. Jus Navigandi, Teresina, ano 8, n.245, 9 mar. 2004. Disponível em: http://jus2.uol.com.br/doutrina/texto.asp?id=4826. Acesso em: 03 nov. 2008.

Anteprojeto de Código Brasileiro de Processos Coletivos. Disponível em: http:// www.pucsp.br/tutelacoletiva/download/cpbc_versão24_02_2006.pdf Acesso em: 07 set. 2009.

BRASIL. Estatuto da Cidade: guia para implementação pelos municípios e cidadãos. Brasília: Câmara dos Deputados, Coordenação de Publicações, 2002.

. Federal Rules of Civil Procedure. Disponível em: $<$ http://www.law.cornell.

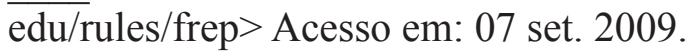

FREITAS FILHO, João Bosco Won Held Gonçalves de. Os modelos de representação dos interesses transindividuais apresentados por Mauro Capelletti. A solução pluralista do direito processual coletivo brasileiro. Jus Navigandi, Teresina, ano 11, n.1512, 22 ago. 2007. Disponível em: http://jus2. uol.com.br/doutrina/texto.asp?id=10311. Acesso em: 22 out.2008.

GÓMEZ, J. Miguel Lobato. Código Civil e Estatuto da Cidade. Jus Navigandi, Teresina, ano 8, n. 247, 11 mar. 2004. Disponível em: http://jus2.uol.com.br/ doutrina/texto.asp?id=4933. Acesso em:28 jun. 200915.

LIMA, Fernando Antônio Negreiros. A intervenção do Ministério Público no processo civil brasileiro como custus legis. São Paulo: Método, 2007.

MENDES, Thays Cristina Ferreira. A ação civil pública e a tutela aos interesses difusos e coletivos. Jus Navigandi, Teresina, ano 12, n.1713,10 mar. 2008. Disponível em: http://jus2.uol.com.br/doutrina/texto.asp?id=11023. Acesso em: 03 nov. 2008.

MILARÉ, ÉDIS (coord.). Ação civil pública: Lei 7.347/1985 - 15 anos. São Paulo: Revista dos Tribunais, 2001.

PILATI, Luciana Cardoso. O sistema brasileiro de ações coletivas e a responsabilidade civil por danos causados ao meio ambiente. Jus Navigandi, Teresina, ano 12, n.1790, 26 maio 2008. Disponível em: http://jus2.uol.com.br/doutrina/ texto.asp?id=11295. Acesso em: 04 nov.2008. 
REGO, Andréa de Fátima de Oliveira. O processo e a sentença coletiva. Jus Navigandi, Teresina, ano 11, n.1235, 18 nov. 2006. Disponível em: http://jus2. uol.com.br/doutrina/texto.asp?id=9185. Acesso em: 23 out. 2008.

SMANIO, GIanpaolo Poggio. A tutela constitucional dos interesses difusos. Jus Navigandi, Teresina, ano 8, n.438, 18 set. 2004. Disponível em: http://jus2. uol.com.br/doutrina/texto.asp?id=5710. Acesso em: 23 out. 2008.

SILVA, José Afonso da. Direito Urbanístico brasileiro. São Paulo: Malheiros, 2006.

\section{PROCESSUAL ISSUES REGARDING TRANSINDIVIDUAL RIGHTS}

Abstract: The main purpose of the present article is to consider the main ways of prosecution and coercion resources to face collective questions, the application of these procedures and main difficulties in order to assure the effective tutorship, where the environmental question can be addressed. The law, to be considered, needs to be understood and applied as a proposal where the meaning modifies itself along by facing the changes in demands and historical, social and ideological facts. This work tries to show that these constant searches for new attitudes and practices are the best way to approach society and justice.

Keywords: Environmental Law. Procedural questions. Innovation. 